\title{
COMPREHENSIVE STUDIES OF ORGANIC AND INORGANIC ADSORBENTS
}

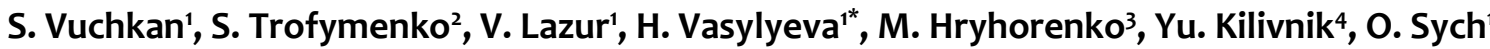 \\ ${ }^{1}$ Department of Theoretical Physics, Uzhgorod National University, Uzhgorod, Ukraine \\ ${ }^{2}$ NAS of Ukraine Chuiko Institute of Surface Chemistry, Kyiv, Ukraine \\ 3NAS of Ukraine Institute for Nuclear Research, Kyiv, Ukraine \\ 4NAS of Ukraine Institute of Sorption and Endoecology Problems, Kyiv, Ukraine
}

\begin{abstract}
The radiation resistance of natural zeolite, cation exchange resin, carbon sorbent, and titanium phosphate were investigated, as well as the ability to adsorb strontium ions after internal adsorbents irradiation. It is shown, that upon irradiation the adsorption properties of all these materials are slightly reduced. The only exception is titanium phosphate with a surface modified with $\mathrm{NH}_{4} \mathrm{OH}$. Initial and residual concentration of stable strontium isotopes was measured by direct complexometric titration. Some experiments were performed with radioactive ${ }^{90} S r$ as well. The amount of ${ }^{9}$ Sr was controlled by liquid scintillation techniques. The values of adsorption of strontium ions by irradiated and non-irradiated samples of amorphous titanium phosphate were determined. The analysis of changes of titanium phosphate surface under the action of external irradiation was conducted by the method of low-temperature nitrogen adsorption-desorption isotherms. The proportion of micro and mesopores, as well as the total surface area of the investigated adsorbent, were estimated. The pore volume and pore radius were calculated by the DFT and BJH methods. A brief comparison of these methods was made.
\end{abstract}

Keywords: Adsorbents, radiation resistance, surface modification, liquid scintillation counting

\section{INTRODUCTION}

Purification of aqueous solutions from radionuclide contamination is an extremely problematic topic, which is the subject of many scientific papers. This scientific topic is very relevant for Ukraine. The aim of this work is a detailed study of the main classes of organic and inorganic adsorbents. In general, adsorbents can be natural (zeolites, kaolin, activated carbon $[1,2]$ ) and synthetic (titanium dioxide [3-6], silicon dioxide and composite materials [7], fumed silica [8, 9], graphene, salts of polyvalent metals $[10,11]$, etc.). A special place among adsorbents is occupied by ion exchange resins, which, as a rule, have an organic matrix, for example, styrene-vinylbenzene with functional groups fixed on it. Ion-exchange resins, along with titanium dioxide and activated carbon, are most widely used in industry to purify aqueous solutions from heavy metal cation and radionuclides [12-15]. Since radioactive elements, for example, ${ }^{90} \mathrm{Sr}$, are sources of ionizing radiation, it is important to study the radiation resistance of adsorbents, which are offered for its extraction and storage [16-19]. For example, in publications [7] authors evaluate the radiation resistance of the cellulose $\mathrm{HO}_{7} \mathrm{Sb}_{3}$ adsorbent by measuring the adsorption coefficient of lanthanum isotopes before and after irradiation. It has been shown that a radiation dose of $50 \mathrm{kGy}$ reduces the adsorption capacity of cellulose $\mathrm{HO}_{7} \mathrm{Sb}_{3}$ by $20 \%$ from the initial. A dose of $150 \mathrm{kGy}$ reduces the adsorption capacity toward lanthanum by $96 \%$ percent which leads to complete degradation of sorbent material.
In this work, we focused on the study of the radiation stability of adsorbents. Natural clinoptilolite, ion exchange resin with sulfonic acid centers as well as synthetic adsorbent titanium phosphate were investigated. Changes in the surface of adsorbents and their ability to adsorb strontium ions before and after irradiation were studied as well.

\section{EXPERIMENTAL TECHNIQUES}

\subsection{Materials and Methods used for experimental} work

Chemicals such as $\mathrm{SrCl}_{2}$ (99.9\% Merck), $\mathrm{HNO}_{3}$, Eriochrom Black T, $\mathrm{NH}_{4} \mathrm{OH}$ and ethylene diamine tetraacetic acid (EDTA) were used as analytical-grade reagents with three step de-ionized water. Liquid scintillation counting of ${ }^{90} \mathrm{Sr}$ and other pure $\beta^{-}$-emitters was performed using spectrometer-radiometer Quantulus-1220 loaded in KINR NAS of Ukraine. Radiation resistance of the adsorbents was investigated using resonant linear electron accelerator "Argus" loaded in Laboratory of Radiation Technology, Institute of Physics, NAS of Ukraine. Surface characteristics of the adsorbent before and after irradiation was investigated by low temperature adsorption-desorption isotherms, which were obtained using equipment Autosorb "Quantachrom Nova” ISPE, NAS of Ukraine.

\footnotetext{
*h.v.vasylyeva@hotmail.com
} 
2.2. Natural and Synthetic Materials with Adsorption Properties

Natural zeolite was extracted from the Sokyrnytskyi deposit of the Transcarpathian region (Ukraine). Cation exchange resin based on styrene-divinylbenzene with an active sulfonic acid functional group also was used in the present work. This ion exchange resin has a crosslinkage of $2 \%$, heating stable up to $100^{\circ} \mathrm{C} ; \sim 80 \%$ loss on drying, $110^{\circ} \mathrm{C}$. It is commercially available, for example, as strong acid cation exchange resin Dowex HCR s/s (Dow Chemical USA) [14].

The third type of adsorbents belongs to the prototypes of adsorbents was titanium phosphate salts of polyvalent metals of amorphous modification. Titanium phosphate was synthesized at the Institute of Sorption and Endoecology Problems (ISPE) of the National Academy of Sciences of Ukraine. Titanium phosphate is a synthetic inorganic sorbent, amorphous modification with a fairly large surface area (150-200 $\mathrm{m}^{2} / \mathrm{g}$ ), which effectively absorbs $235 \mathrm{U}$ fission products from aqueous solutions $[10,11]$. The uniqueness of this sorption material lies in the possibility of its synthesis both in crystalline and amorphous modifications, as well as with different ratios of phosphorus: titanium $(\mathrm{P} / \mathrm{Ti})$ in the sample. These studies were carried out with titanium phosphate with a ratio of $(\mathrm{P} / \mathrm{Ti})=1.25$. The study of surface characteristics was carried out in ISPE NAS of Ukraine using low-temperature nitrogen adsorption-desorption isotherms and BET theory of adsorption. Pore size distribution from nitrogen adsorption-desorption isotherms using the non-local density functional theory (DFT) with an equilibrium model based on cylindrical pores in silica, and BJHmethod, based on Kelvin equation were conducted as well.

\subsection{Investigation of Adsorbent Radiation Resistance}

Radiation resistance of adsorbent samples was investigated on a resonant linear electron accelerator "Argus" loaded in Laboratory of Radiation Technology, Institute of Physics, NAS of Ukraine. The average energy of the electrons generated in the pulse mode was $1 \mathrm{MeV}$. The electron flux was $1,25^{\cdot} 10^{15}-1,25^{\cdot} 10^{16}$ electron $/ \mathrm{cm}^{2} \cdot \mathrm{s}$. The irradiation dose was $2 \cdot 10^{3} \mathrm{~Sv}$. The investigations were performed in two series. The irradiation of adsorbents was performed in the first series without any additional chemical modified surface. In the second series, the surface of titanium phosphate interacts with $10 \% \mathrm{NH}_{4} \mathrm{OH}$ and then was irradiated. The adsorption capacity of the adsorbent toward strontium cations was chosen as an indicator of its radiation resistance, according to [7]. However, in present investigations, the changes of adsorbents surface characteristics were conducted as well.

\subsection{Batch adsorption studies}

Adsorption investigations were performed in a batch mode with the liquid: solid (L:S) phase ratio equal to 50 $\left(m_{\mathrm{ads}}=0.1 \mathrm{~g}, V_{\mathrm{sol}}=5 \mathrm{ml}\right)$. Initial and residual concentrations of strontium ions were conducted using direct complexometric titration with Eriochrom Black $\mathrm{T}$. In some experiments, the radioactive ${ }^{\circ} \mathrm{Sr}$ and Liquid scintillation counting were performed. All experiments were repeated at least two times. Adsorption values were calculated by the formula (1):

$$
q_{e}=\frac{\left[\left(C_{o}-C_{e}\right) V\right]}{m}
$$

where $\mathrm{q}_{\mathrm{e}}-$ is the amount of adsorbate uptake, $\mathrm{mg} / \mathrm{g} ; \mathrm{C}_{\mathrm{o}}$ and $\mathrm{C}_{\mathrm{e}}-$ are initial and residual concentrations of adsorbate, $\mathrm{mg} / \mathrm{L} ; \mathrm{V}$ - is volume of solution, $\mathrm{L} ; \mathrm{m}$ - is mass of adsorbent, $\mathrm{g}[6,9]$.

The test experiments were performed with an initial concentration of $\mathrm{Sr}^{2+}$ cations in the form of $\mathrm{SrCl}_{2}$ for evaluated the radiation resistance of the investigated adsorbents. As noted, some experiments were conducted with active ${ }^{\circ} \mathrm{Sr}$ (without carrier) with some

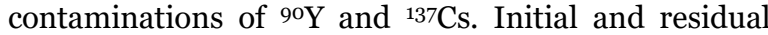
activity was controlled using Liquid Scintillation Counting.

\subsection{Liquid Scintillation Counting of ${ }^{\circ \circ} \mathrm{Sr}$}

The quantity of ${ }^{90} \mathrm{Sr}$ from soil extract (from Chornobyl Exclusion Zone) was controlled by Liquid scintillation counting using a low-background liquid scintillation spectrometer-radiometer Quantulus-1220 loaded in KINR NAS of Ukraine. Each of the measured samples was diluted with an organic scintillator Optiphase "Hisafe" 3 up to a volume of $20 \mathrm{ml}$ and elements spectra were obtained. (During $10 \mathrm{~min}$ ). The

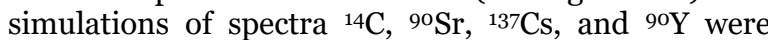
conducted, using the IAEA Library database and Geant 4 to determine the detection conditions of $\beta^{-}$- spectra of the Quantulus-1220 installed in KINR Kyiv.

\section{RESULTS AND DISCUSSION}

\subsection{Changes of Textural Characteristics of} Titanium Phosphate Before and After Irradiation

The changing in textural characteristics of the samples of titanium phosphate was the most detailed studied. The results are shown in Table 1 and 1(a). Ionexchange resin retained its adsorption ability concerning strontium cation, however, after irradiation it became gel-shaped. We must note that very often ion exchange resins are used in the gel-shaped form, conducting the so-called extraction of radionuclides with these adsorbents. However, we could not investigate the change in its textural characteristics. The zeolite's ability to adsorb strontium cations significantly decreased after irradiation (Table 2) and therefore we paid the greatest attention to titanium phosphate.

This adsorption material showed significant radiation resistance, as well as with the use of a combination of irradiation and chemical modification of the surface, its ability to adsorb $\mathrm{Sr}^{2+}$ cation was increased.

If we compare methods for assessing surface changes, then according to Table 1 and 1(a), and Fig. 2 (a) and (b), it is clear that the DFT method is more sensitive to changes in adsorption porosity. BJH (Barrett-Joyner-Halenda) method is a classical macroscopic method, which is based on the assumption of a certain pore-filling mechanism. The method based on the Kelvin equation is linked to the pore condensation phenomena. It is applicable for mesopore size analysis. This method was chosen since titanium phosphate is mesoporous material. In contrast to these macroscopic approaches, the Density Functional Theory (DFT) method provides not only a microscopic model of adsorption. This theory, which is based on 
statistical mechanics, connects macroscopic properties to molecular behavior. Therefore, to achieve a more realistic description of adsorption phenomena and an accurate and comprehensive pore size analysis, methods such as the DFT of inhomogeneous fluids and Monte Carlo simulations, which bridge the gap between the molecular level and macroscopic approaches are preferable. It records an increase in the radius of pores (and a decrease in their volume) during immediate. Therefore, in the study of changes in the texture characteristics of mesoporous materials, the DFT method of surface analysis can be recommended.

Table 1. Changes in textural characteristics of titanium phosphate before and after irradiation

\begin{tabular}{|c|c|c|c|}
\hline Sample & $\begin{array}{c}\text { Surface } \\
\text { area, } \mathrm{m}^{2} / \mathrm{g} \\
\text { BET }\end{array}$ & $\begin{array}{c}\text { Surface area, } \\
\mathrm{m}^{2} / \mathrm{g} \text { (ads) } \\
\text { BJH }\end{array}$ & $\begin{array}{c}\text { Surface } \\
\text { area, } \mathrm{m}^{2} / \mathrm{g} \\
\text { DFT }\end{array}$ \\
\hline 1 & 182 & 150.8 & 173 \\
\hline $2^{*}$ & 179 & 149 & 168 \\
\hline \multicolumn{4}{|c|}{ Surface area after irradiation } \\
\hline 3 & 155.3 & 138 & 150.9 \\
\hline $4^{*}$ & 152.5 & 133.7 & 147.2 \\
\hline 5 & 147.1 & 119.8 & 137.2 \\
\hline
\end{tabular}

Table 1(a). Changes in textural characteristics of titanium phosphate before and after irradiation

\begin{tabular}{|c|c|c|c|c|}
\hline Sample & $\begin{array}{c}\text { Pore } \\
\text { volume } \\
\mathrm{m}^{3} / \mathrm{g} \\
\text { BJH }\end{array}$ & $\begin{array}{c}\text { Pore } \\
\text { volume, } \\
\mathrm{m}^{3} / \mathrm{g} \\
\mathrm{DFT}\end{array}$ & $\begin{array}{c}\text { Pore } \\
\text { radius } \\
\text { BJH }\end{array}$ & $\begin{array}{c}\text { Pore } \\
\text { radius } \\
\mathrm{DFT}\end{array}$ \\
\hline 1 & 0.604 & 0.6159 & 58.11 & 69.2 \\
\hline $2^{*}$ & 0.59 & 0.606 & 58.59 & 67.33 \\
\hline \multicolumn{5}{|c|}{ Pore size distribution after irradiation } \\
\hline 3 & 0.5268 & 0.528 & 57.84 & 56.42 \\
\hline $4^{*}$ & 0.521 & 0.524 & 57.8 & 56.42 \\
\hline 5 & 0.4884 & 0.494 & 57.89 & 67.33 \\
\hline
\end{tabular}

* Samples 2 and 4 were treated with ammonia

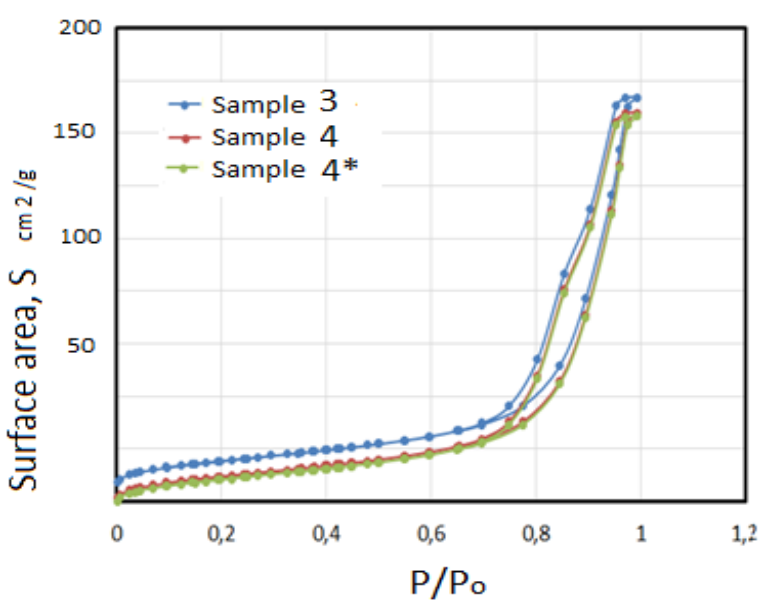

Figure 1. Typical nitrogen adsorption-desorption isotherm for titanium phosphate. Samples 3 and 4 were irradiated; sample $4^{*}$ - was treat by $\mathrm{NH} 4 \mathrm{OH}$ with further irradiation.

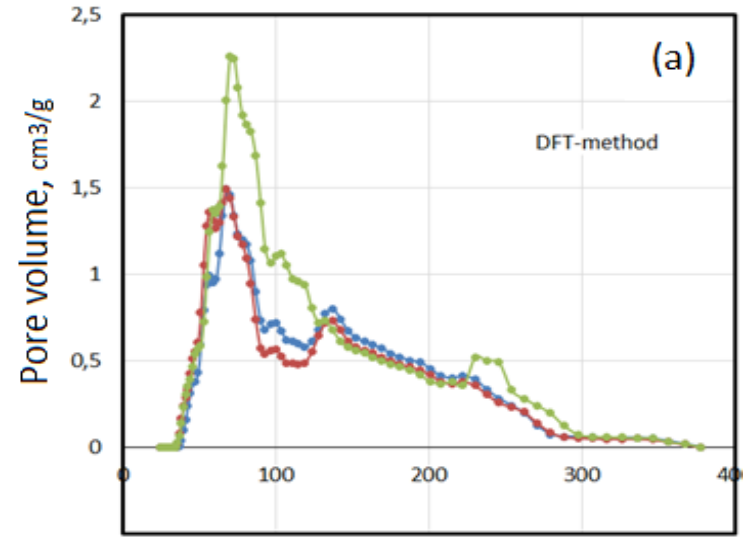

Pore radius, $\mathrm{A}$

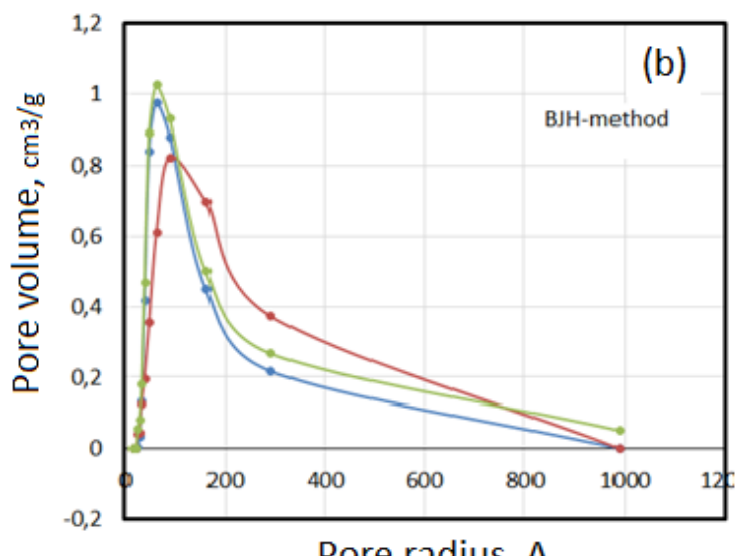

Pore radius, $\mathrm{A}$

Figure 2. Pore size distribution from nitrogen adsorption-desorption isotherms using the non-local density functional theory (DFT) with an equilibrium model based on cylindrical pores in silica (a) and BJH-method, based on Kelvin equation (b).

\subsection{Adsorption of Strontium Ions by Irradiated and Non-Irradiated Adsorbents}

Table 2. Adsorption of strontium ions by irradiated and non-irradiated adsorbents

\begin{tabular}{|c|c|c|}
\hline Adsorbent & $\begin{array}{c}\text { Adsorption } \\
\text { values by } \\
\text { non-irradiated } \\
\text { adsorbents } \\
\text { q, mmol/g }\end{array}$ & $\begin{array}{c}\text { Adsorption } \\
\text { values } \\
\text { by irradiated } \\
\text { adsorbents } \\
\text { q, mmol/g }\end{array}$ \\
\hline $\begin{array}{c}\text { Natural } \\
\text { clinoptilolite }\end{array}$ & $0.0125 \pm 0.002$ & 0.00 \\
\hline $\begin{array}{c}\text { Ion exchange } \\
\text { resin with } \\
\text { sulfonic acid } \\
\text { centers }\end{array}$ & $0.185 \pm 0.009$ & $0.139 \pm 0.011$ \\
\hline $\begin{array}{c}\text { Titanium } \\
\text { phosphate }\end{array}$ & $0.0623 \pm 0.055$ & $0.0153 \pm 0.004$ \\
\hline $\begin{array}{c}\text { Titanium } \\
\text { phosphate } \\
\text { with modified } \\
\text { surface by } \\
\mathrm{NH}_{4} \mathrm{OH}\end{array}$ & $0.1573 \pm 0.012$ & $0.2373 \pm 0.025$ \\
\hline
\end{tabular}


As it can be seen from Table 2, the adsorption ability of all adsorbents decreases after irradiation. Natural unmodified zeolite completely loses the ability to adsorb $\mathrm{Sr}^{2+}$ cations. A slight decrease in the adsorption capacity of the cation-exchange resin is associated with the rupture of the styrene-divinylbenzene matrix under the action of electrons with an energy of $1 \mathrm{MeV}$. However, since adsorption by resin occurs onto sulfonic acid groups, the adsorption ability of the resin only slightly decreases under irradiation. The decrease in the adsorption capacity of titanium phosphate is associated with a decrease in the surface area of the adsorbent. Since the adsorption of metal cations by titanium phosphate does not occur strictly according to the ionexchange mechanism, and in this process, the entire surface of the adsorbent is involved, the effect of ionizing radiation on the adsorption properties of titanium phosphate is stronger than on the adsorbing properties of the ion-exchange resin. However, titanium phosphate does not lose its granular form.

During the interaction between the surface of titanium phosphate and molecules of ammonia and subsequent irradiation, ammonia molecules are impregnated into the surface of titanium phosphate. This phenomenon increases the ability of titanium phosphate to absorb strontium cation.

It is known that the adsorption of $\mathrm{Sr}^{2+}$ cations onto various surfaces is higher in the alkaline environment $[3-5,18]$. The surface of the adsorbent can be partially alkaline, as was described in publication [18], which increases the adsorption of heavy metal cations.

Our assumption of impregnation of ammonia molecules into the surface of titanium phosphate has been confirmed by IR spectra, which are shown in Figure 3

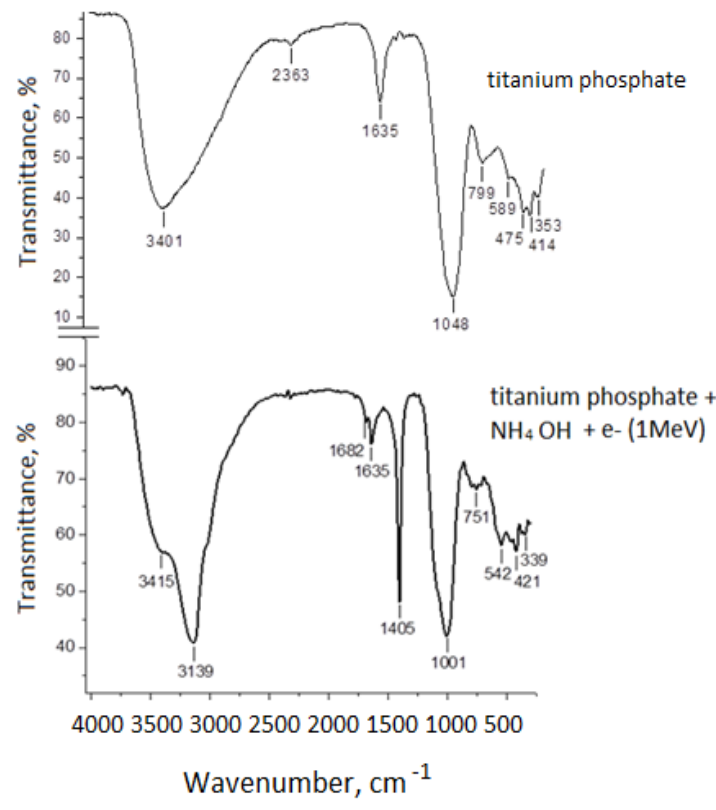

Figure 3. IR spectrum of amorphous titanium phosphate (ratio Phosphorus/Titanium=1.25) after chemical modification of the surface and irradiation. The line $1405 \mathrm{~cm}^{-1}$ corresponds to deformed oscillations of ammonia (ammonium groups).
At the same time, the textural characteristics of titanium phosphate have not changed after chemical modification. Therefore, this method can be considered a method of modifying the surface of titanium phosphate, which leads to an increase in the adsorption ability of this material concerning strontium cation almost twice. These results are in good agreement with the results describes in the publication [19].

\subsection{Adsorption of ${ }^{90} \mathrm{Sr}$}

The adsorption ability of the examined adsorbents was confirmed using ${ }^{\circ 0} \mathrm{Sr}$ radionuclide [5, 20-22]. The obtained results were tested using a radioactive isotope of ${ }^{\circ} \mathrm{Sr}$ (with micro impurities of ${ }^{137} \mathrm{Cs}$ and ${ }^{\circ} \mathrm{Y}$ ) the initial and residual concentration of which was investigated by liquid scintillation counting. The model of the sample with a scintillator is shown in Fig.4.

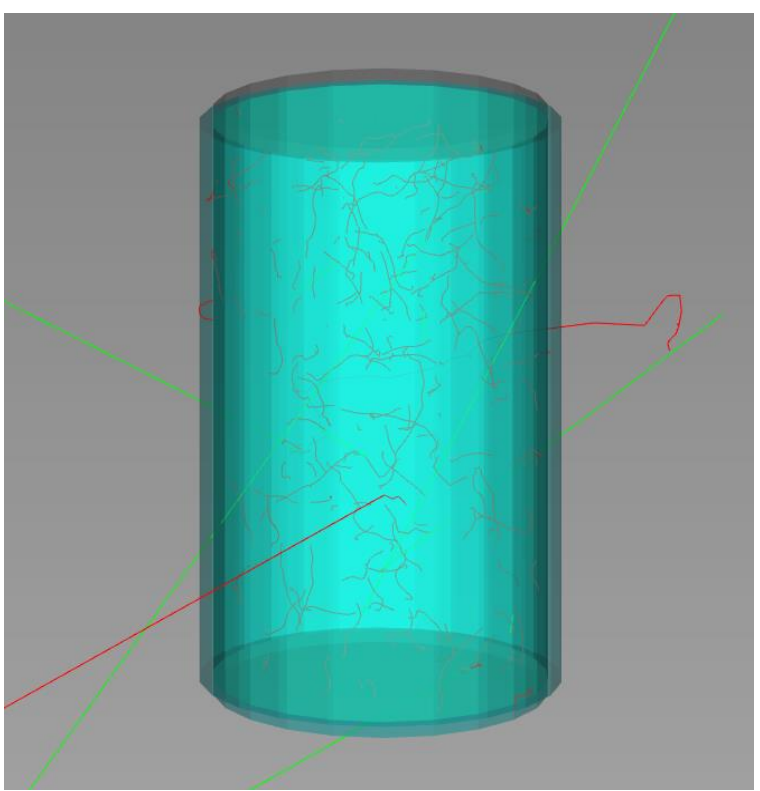

Figure 4. Model of the sample with scintillator.

The experimental LSC spectrum of the initial

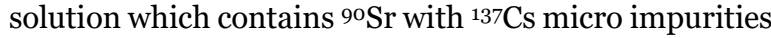
is shown in Fig. 5. The processed spectrum of ${ }^{90} \mathrm{Sr}$, and ${ }^{90} \mathrm{Sr}$ with micro-impurities of ${ }^{137 \mathrm{Cs}}$ are shown in Fig.6 and Fig.7 respectively.

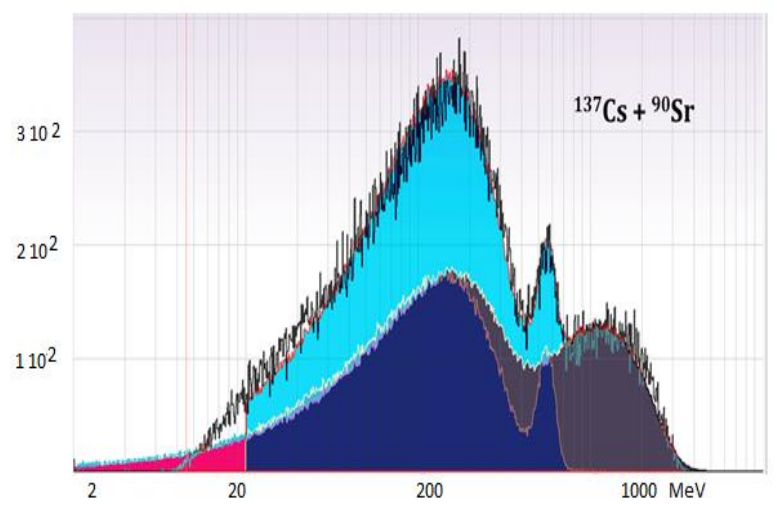

Figure 5. Experimental LSC spectrum of solution which contains ${ }^{90} \mathrm{Sr}$ with ${ }^{137} \mathrm{Cs}$ micro impurities. 


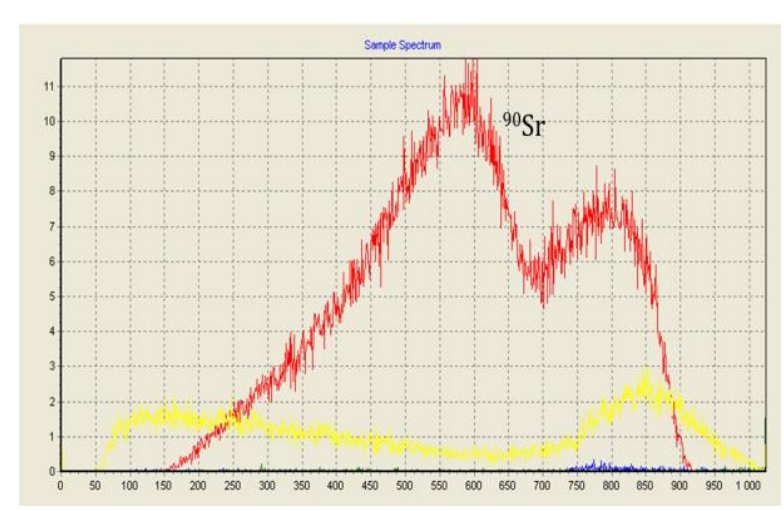

Figure 6. Experimental $\beta^{-}$- spectrum of ${ }^{90} \mathrm{Sr}$ sample obtained with Quantulus-1220.

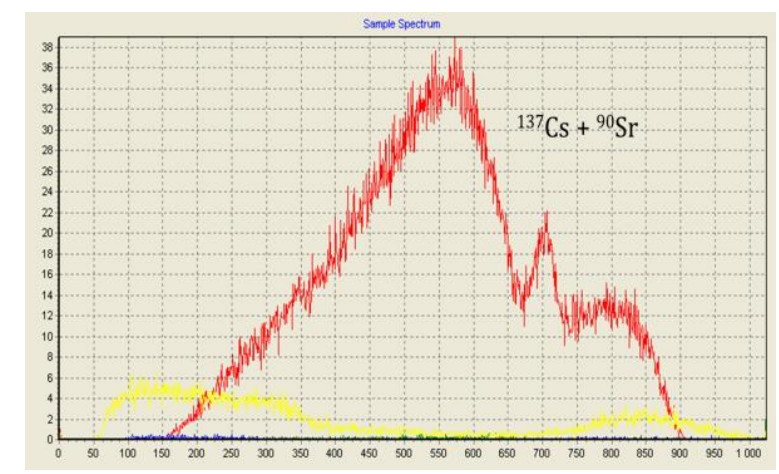

Figure 7. Experimental $\beta^{-}$- spectrum of a solution containing

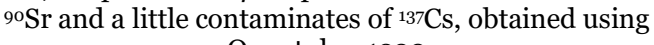
Quantulus-1220

In spectra, which are shown in Fig. 6 and Fig.7 the no sifting and questing of the experimental spectrum.

The activity $[\mathrm{A}]$ of the solution containing strontium was ${ }^{90} \mathrm{Sr} 64 \pm 0.4 \mathrm{~Bq}$. During the interaction of radioactive solution with the modified titanium phosphate, strontium activity decreased almost by $70 \%$. That is, $70 \%$ of all activity was adsorbed. Residual activity is mainly due to impurities of ${ }^{137} \mathrm{Cs},{ }^{90} \mathrm{Y}$, which were also presented in investigated solution according to the LS spectrum (Fig.4). Titanium phosphate turned slightly yellow, due to interaction of water radiolysis product with titanium atoms on its surface:

$$
\begin{aligned}
& \mathrm{H}_{2} \mathrm{O} \sim \mathrm{e}^{-}{ }_{[a q]}, \mathrm{H}, \mathrm{OH} \cdot, \mathrm{H}_{2} \mathrm{O}_{2}, \mathrm{H}^{+}{ }_{[a q]}, \mathrm{OH}^{-}{ }_{[a q]}, \\
& \mathrm{Ti}(\mathrm{IV})+\mathrm{H}_{2} \mathrm{O}_{2} \rightarrow(\mathrm{pH}<7) \rightarrow \mathrm{Ti}(\mathrm{O}-\mathrm{O})^{2+} \ldots-
\end{aligned}
$$

yellow color

$\mathrm{Ti}(\mathrm{IV})+\mathrm{H}_{2} \mathrm{O}_{2} \rightarrow(\mathrm{pH} \approx 7) \rightarrow \mathrm{Ti}(\mathrm{O}-\mathrm{OH})(\mathrm{OH}) . .-$ (yellow color)

$$
\mathrm{Ti}(\mathrm{IV})+\mathrm{H}_{2} \mathrm{O}_{2} \rightarrow(\mathrm{pH}>7) \rightarrow \mathrm{Ti}(\mathrm{O}-\mathrm{O})_{4} 4^{-} \ldots-
$$

orange color

Interaction of natural zeolite with an aqueous solution containing ${ }^{90} \mathrm{Sr}$ has shown, that almost all activity remained in the solution.

\section{CONCLUSION}

The investigations of radiation stability of adsorbents were performed. Changes in their structural characteristics, as well as adsorption ability toward Sr2+ cations, were controlled.
It was shown, that the DFT method is more sensitive to changes in adsorption porosity, compared with the BJH method. DFT method can be preferable in the study of changes in the textural characteristics of mesoporous materials under irradiation.

The adsorption ability of all adsorbents without modification decreases after irradiation.

Phenomena of impregnation of molecules of ammonia into the titanium phosphate surface increases the ability of titanium phosphate to absorb strontium cation. Modified titanium phosphate, decreases ${ }^{90} \mathrm{Sr}$ activity almost by $70 \%$.

Acknowledgements: The authors are thankful to Prof. Doubeshko G. for helping with radiation resistance investigations and Prof. Mironyuk I. for providing IR analysis.

\section{REFERENCES}

1. H. Vasylyeva et al., "Adsorption of zirconium ions by X-type zeolite,” Biointerface Res. Appl. Chem., vol. 11, no. 5, pp. 13421 - 13431, Feb. 2021. DOI: $10.33263 /$ BRIAC115.1342113431

2. N. V. Sych et al., "Porous structure and surface chemistry of phosphoric acid activated carbon from corncob," Appl. Surf. Sci., vol. 261, pp. 75 - 82, Nov. 2012.

DOI: 10.1016/j.apsusc.2012.07.084

3. Y. Takahatake, A. Shibata, K. Nomura, T. Sato, "Effect of Flowing Water on Sr Sorption. Changes of Hydrous Sodium Titanate," Minerals, vol. 7, no. 12, 247, Dec. 2017. DOI: $10.3390 / \mathrm{min} 7120247$

4. I. Mironyuk, T. Tatarchuk, H. Vasylyeva, M. Naushad, I. Mykytyn, "Adsorption of Sr(II) cations onto phosphated mesoporous titanium dioxide: Mechanism, isotherm and kinetics studies," J. Environ. Chem. Eng., vol. 7, no. 6, 103430, Dec. 2019.

DOI: $10.1016 /$ j.jece.2019.103430

5. I. F. Mironyuk, I. M. Mykytyn, O. Y. Kaglyan, D. I. Gudkov, H. V. Vasylyeva, "9oSr adsorption from the aquatic environment of Chornobyl exclusion zone by chemically enhanced TiO2," Nucl. Phys. At. Energy, vol. 21, no. 4, pp. 347 - 353, Dec. 2020.

DOI: $10.15407 /$ jnpae2020.04.347

6. H. Vasylyeva, I. Mironyuk, I. Mykytyn, K. Savka, "Equilibrium studies of yttrium adsorption from aqueous solutions by titanium dioxide," Appl. Radiat. Isot., vol. 168, 109473, Feb. 2021. DOI: 10.1016/j.apradiso.2020.109473 PMid: 33658128

7. E. A. Abdel-Galil, H. Moloukhia, M. Abdel-Khalik, S. S. Mahrous, "Synthesis and physico-chemical characterization of cellulose $/ \mathrm{HO}_{7} \mathrm{Sb}_{3}$ nanocomposite as adsorbent for the removal of some radionuclides from aqueous solutions," Appl. Radiat. Isot., vol. 140, pp. $363-373$, Oct. 2018.

DOI: $10.1016 /$ j.apradiso.2018.07.022 PMid: 30142577

8. I. F. Mironyuk et al., "Effects of enhanced clusterization of water at a surface of partially silylated nanosilica on adsorption of cations and anions from aqueous media," Microporous Mesoporous Mater., vol. 277, pp. 95 - 104, Mar. 2019.

DOI: $10.1016 /$ j.micromeso.2018.10.016

9. I. F. Mironyuk, H. V. Vasylyeva, V. I. Mandzyuk, N. A. Bezruka, T. V. Dmytrotsa, "The kinetics of adsorption binding of $\mathrm{Ba}+$ ions by 
trimethylsilylated silica," Phys. Chem. Solid State, vol. 19, no. 1, pp. 66 - 73, Mar. 2018. DOI: $10.15330 /$ pcss.19.1.66-73

10. H. V. Vasylyeva et al., "Radiochemical studies of state of lanthanum microamounts in water solution," J. Mol. Liq., vol. 118, no. 1 - 2, pp. 41 - 44, Apr. 2005. DOI: 10.1016/j.molliq.2004.07.008

11. V.V. Strelko, "New sol-gel processes in the synthesis of inorganic sorbents and ion exchangers based on nanoporous oxides and phosphates of polyvalent metals," J. Solgel Sci. Technol., vol. 68, no. 3, pp. 438 - 446, Mar. 2013.

DOI: 10.1007/s10971-013-2990-0

12. J. J. Surman, J. M. Pates, H. Zhang, S. Happel, "Development and characterization of a new $\mathrm{Sr}$ selective resin for the rapid determination of ${ }^{90} \mathrm{Sr}$ in environmental water samples," Talanta, vol. 129, pp. 623-628, Nov. 2014.

DOI: $10.1016 /$ j.talanta.2014.06.041 PMid: 25127642

13. H. Tazoe, "Novel method for low level Sr-9o activity detection in seawater by combining oxalate precipitation and chelating resin extraction," Geochem. J., vol. 51, no. 2, pp. 193 - 197, Mar. 2017. DOI: 10.2343/geochemj.2.0441

14. M. M. S. Ali, E. A. Abdel-Galil, M. M. Hamed, "Removal of strontium radionuclides from liquid scintillation waste and environmental water samples," Appl. Radiat. Isot., vol. 166, 109357, Dec. 2020.

DOI: 10.1016/j.apradiso.2020.109357

PMid: 32755756

15. A. Surrao et al., "Improving the separation of strontium and barium with Sr Resin using chelating eluent solutions," J. Radioanal. Nucl. Chem., vol. 319, no. 3, pp. 1185 - 1192, Jan. 2019.

DOI: 10.1007/s10967-019-06432-w

16. V. J. Angadi et al., "Mechanism of $\gamma$-irradiationinduced phase transformations in nanocrystalline Mno.5Zno.5Fe2O4 ceramics," J. Solid State Chem., vol. 246, pp. 119 - 124, Feb. 2017.

DOI: 10.1016/j.jssc.2016.11.017

17. H. M. Khalid, M. T. Rahman, M. K. Basher, M. J. Afzal, M. S. Bashar, "Impact of ionizing radiation doses on nanocrystalline $\mathrm{TiO} 2$ layer in
DSSC's photoanode film," Results Phys., vol. 11, pp. 1172 - 1181, Dec. 2018. DOI: $10.1016 /$ j.rinp.2018.10.006

18. I. Mironyuk, I. Mykytyn, H. Vasylyeva, K. Savka, "Sodium-modified mesoporous TiO2: Sol-gel synthesis, characterization and adsorption activity toward heavy metal cations," J. Mol. Liq., vol. 316, 113840 , Oct. 2020.

DOI: $10.1016 /$ j.molliq.2020.113840

19. Г. Васильєва, В. Яковлев, Ю. Килівник, М. Циба, "Вплив модифікування поверхні фосфату титану на його здатність поглинати йони стронцію із водних розчинів," Фізика і хімія твердого тіла, т. 17, но. 4, с. 548 - 551, Грудень 2016.

(H. Vasylyeva, M. Tsyba, Yu. Kylivnyk, V. Yakovlev, "The Influence of Chemical Modificate of Surface of Titanium Phosphate on its Ability to Sorb Strontium Ions from Aqueous Solutions," Phys. Chem. Solid State, vol. 17, no. 4, pp. 548 - 551, Dec. 2016.)

DOI: $10.15330 /$ pcss.17.4.548-551

20. А. Е. Каглян та інші, "Radionuklidy v aborigennykh vidakh ryb Chernobyl'skoj zony otchuzhdeniya," Ядерна фізика та енергетика, т. 13, но. 3, c. $306-315,2012$.

(A. Ye. Kaglyan et al., "Radionuclides in the indigenous fish species of the Chernobyl exclusion zone," Nucl. Phys. At. Energy, vol. 13, no. 3, pp. $306-315,2012$.)

Retrieved from:

http://jnpae.kinr.kiev.ua/13.3/Articles PDF/jnpae -2012-13-0306-Kaglyan.pdf

Retrieved on: Dec. 15, 2020

21. Yu. Kilivnik, S. Vuchkan, I. Syika, H. Vasylyeva, O. Sych, "Purification of aqueous solutions from strontium ions by natural and synthetic sorbents under increased radiation background," in Book of Abstr. $9^{\text {th }}$ Int. Conf. Radiation and Applications in Various Fields of Research ( $R A D$ 2021), Herceg Novi, Montenegro, 2021, p. 62.

DOI: 10.21175/rad.abstr.book.2021.11.4

22. S. Agostinelli et al., "Geant4 - a simulation toolkit," Nucl. Instrum. Methods Phys. Res. A, vol. 506, no. 3, pp. $250-303$, Jul. 2003.

DOI: $10.1016 /$ So168-9002(03)01368-8 